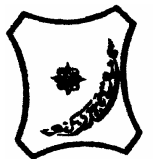

Bayero Journal of Pure and Applied Sciences, 4(1): 1 - 9

Received: October, 2010

Accepted: May, 2011

ISSN $2006-6996$

\title{
OPTIMISATION STUDY ON THE PRODUCTION OF ANAEROBIC DIGESTATE COMPOST FOR APPLICATION ON ARABLE SOILS
}

\author{
a Abdullahi", Y.A., ' Suleiman, S.S. and 'Akunna, J.C., \\ ${ }^{a}$ Department of Environmental Science, Kaduna Polytechnic, Nigeria \\ 'Department of Applied Science, Kaduna Polytechnic, Nigeria \\ 'Urban Water Technology Centre, University of Abertay Dundee, United Kingdom \\ *Correspondence author:aayusuf@msn.com
}

\begin{abstract}
Organic fraction of municipal solid waste (OFMSW) is a rich substrate for biogas and compost production. Anaerobic Digestate compost (ADC) is an organic fertilizer produced from stabilized residuals of anaerobic digestion of OFMSW. This paper reports the result of studies carried out to optimise the production of ADC from organic fractions of domestic wastes and the effects of ADC amendments on soil quality. In general, ADC amended soils showed greater bioactivity and soil biomass compared to unamended soils. The diversity of soil community structures also increased with increasing ADC amendments with fungal populations showing greater variation than bacteria, suggesting that ADC amendment has greater impact on fungi than bacteria. It was found that seed germination in ADC amended soils increased with dilution and incubation time, suggesting that lower ADC application rates and longer lag periods between soil applications and planting can improve the benefits of ADC as an amendment for arable soil.
\end{abstract}

Keywords: Anaerobic digestion; anaerobic digestate compost; food waste; green waste, postaerobic digestion; soil quality

INTRODUCTION

Organic fraction of municipal solid waste (OFMSW) is rich in carbon which can be recovered as biogas and soil fertilizer. As soil quality deteriorates with decreasing soil organic matter, the demand for organic soil amendments continue to rise for sustainable soil management applications. The practice of disposing OFMSW to landfills is no longer considered sustainable (CEC Landfill Directive, 1999). Current regulations and management techniques in European countries promote integration, source separation, biogas recovery and the use of residual anaerobic digestates of OFMSW as soil improvers (DEFRA, 2004). The optimisation of biogas recovery and production of quality compost as promoted in sustainable management of OFMSW will depend on the quality and stability of substrates as well as anaerobic and aerobic stabilisation techniques employed.

Although OFMSW are heterogeneous in nature, it is primarily made up of food and green wastes. These waste types can be separated at source and used as substrates for biogas production (Hartmann and Ahring, 2006; Mata-Alvarez et al., 1990). A major challenge of anaerobic digestion of food and green wastes is $\mathrm{pH}$ stability which may occur because of the differential biodegradation rates of the substrates (Bolzonella et al., 2006; Mata-Alvarez et al., 2000; Kayhanian, 1995). The residual digestate can be stabilised by aerobic treatment into organic soil fertilizer, referred in this paper as anaerobic digestate compost (ADC). Large scale use of organic fertilizers for soil improvement and increased productivity is generally limited due to problems associated with stability and maturity (Levy and Taylor, 2003). The use of fresh and non stabilised organic matter for soil improvement may lead to phytotoxicity and deteriorating soil quality (Tiquia and Tam, 1998; Jimenez and Garcia, 1989). On the other hand amendment with stable organic matter may result in increased fertility and productivity (Shiralipour et al., 1994).

Soil bioactivity is one of the methods used to predict the impact of organic matter application in the soil environment (Pennanen et al., 2004; Ritz and Wheatley, 1989). Seed germination tests are widely used to establish compost stability and maturity (Rajbanshi et al., 1998; Murillo et al., 1995) while the impact of compost application on the biological quality of soils can be assessed by monitoring the activity, size and structure of soil microbial communities (Kowaljow and Mazzarino, 2007; Pennanen et al., 2004; Lin and Brookes, 1999). The diversity of soil microbial communities is critical for optimal soil functioning particularly where organic fertilizers are the principal source of nutrients (Crecchio et al., 2004). From the above discussions, it is clear that the effects of the traditional compost on the physical, chemical and biological properties of soil are well documented. However, limited studies have been undertaken on the effect of ADC on soils despite the importance of ADC in the modern OFMSW management practices. The study reported in this paper, thus, evaluates the effects of ADC produced from the organic fractions of domestic wastes on biological properties of soil. 


\section{MATERIALS AND METHODS}

Batch digestion of domestic waste feedstocks comprised of various proportions of food and green wastes was first carried out to identify suitable waste combination that can ensure $\mathrm{pH}$ stability during digestion and optimum biogas production.

Thereafter, the digestate of the most suitable waste combination was aerobically treated (i.e. composting process) until the resulting compost (ADC) was deemed stable and mature (stable $\mathrm{pH}$ and carbon/nitrogen ratio were used as indicators of ADC stability and maturity). The ADC was subsequently used for experiments designed to assess its impacts on the biological quality of soils. Population diversity was investigated by Terminal-restriction fragment length polymorphism (T-RFLP) (Marsh, 1999).

\section{Preparation of feedstock and batch cultures}

Laboratory simulated feedstock was a mixture of food waste (FW) and green waste (GW). FW was a blended mixture of food components namely cooked pasta $(22 \%)$, cooked meat $(9 \%)$, lettuce $(11 \%)$, carrots $(3 \%)$, potato $(44 \%)$ and milk $(11 \%)$ while GW was a combination of garden waste (grass) and wood chips in the ratio $3: 1$. The anaerobic sludge (AS) used as seed was obtained from a mesophilic anaerobic reactor treating wastewater from a paper mill. Batch studies were carried out using various proportions of FW and GW and AS, viz; A(FW 80\%, AS 20\%); B(FW $40 \%$, GW 40\%, AS 20\%); C(FW 60\%, GW 20\%, AS $20 \%) ; \mathrm{D}(\mathrm{GW} 60 \%$, FW $20 \%$, AS $20 \%$ ) and $\mathrm{E}(\mathrm{GW}$ $80 \%$ and AS $20 \%$ ). The total solids content of all the cultures at the start of digestion were 19.1, 37.4, $31.0,44.6$ and $53.0 \%$ respectively for cultures A, B, C, $\mathrm{D}$ and $\mathrm{E}$. All the cultures were later subjected to 15 days anaerobic digestion at $55^{\circ} \mathrm{C}$, during which $\mathrm{pH}$, biogas, total solids (TS) and total volatile solids (TVS) were monitored.

\section{Production of anaerobic digestate compost (ADC) from anaerobic digestate}

Approximately eight kilogram $(8 \mathrm{~kg}$ ) of the digestate obtained from the most suitable waste combination was seeded with $10 \%$ of mushroom compost obtained from a nearby farm and aerated in a closed reactor by pumping air into the digestate intermittently for 5 hours daily for ten weeks. In the first five weeks the vessel was maintained at $55^{\circ} \mathrm{C}$, the following three weeks at $35^{\circ} \mathrm{C}$ and the last two weeks at $25^{\circ} \mathrm{C}$. Samples were collected at different times during the aerobic post-treatment period for subsequent analysis.

\section{Preparation of Soil-ADC amendments mixtures}

Soil cores were made from plastic pipes $(40 \mathrm{~mm}$ height $x 50 \mathrm{~mm}$ diameter) with a volume of $78.6 \mathrm{~cm}^{3}$. The base of each core was covered with fine net strong enough to prevent soil drop, but which would not obstruct air and water movement. Soil was a loamy arable soil collected from an experimental plot located at the lower Pilmore of the Scottish Crop Research Institute (SCRI), Dundee, Scotland (GPS $56^{\circ}$ $27^{\prime \prime} 15^{\prime} \mathrm{N}, 03^{0} 04^{\prime \prime} 45^{\prime} \mathrm{W}$, No 3348629620). The soil was passed through a $4 \mathrm{~mm}$ sieve and its $\mathrm{pH}$ and water content determined. The soil's water content was then adjusted to its Water Holding Capacity (WHC) and allowed to stand for twenty four hours. The soil was subsequently divided into 5 fractions, the $1^{\text {st }}$ which represented a blank without added ADC, whilst the $2^{\text {nd }}, 3^{\text {rd }}, 4^{\text {th }}$, and $5^{\text {th }}$ fractions were amended with ADC at the rate of 10, 20, 50 and 100 tonnes/hectare ( $\mathrm{t} \mathrm{ha}^{-1}$ ) respectively.

\section{Soil respiration and biomass}

A total of 30 soil-ADC amendments comprising 6 replicates of 5 amendments (i.e. $10,20,50,100 \mathrm{t} \mathrm{ha}^{-1}$ and the unamended control or $0 \mathrm{t} \mathrm{ha}^{-1}$ ) were incubated for respiration analysis after which they were used for biomass analysis. During respiration studies each soil core was placed inside a sealed 500 $\mathrm{ml}$ Kilner jar and incubated at $15^{\circ} \mathrm{C}$ for 80 days, during which $\mathrm{CO}_{2}$ evolution was monitored. $\mathrm{CO}_{2}$ production was measured by extracting $2 \mathrm{ml}$ of gas from the jar headspace with a syringe analysis and analysing the collected gas by gas chromatography.

Soil biomass estimation was carried out by Substrate Induced Respiration (SIR) as described by Pennanen et al. (2004). Ten gram $(10 \mathrm{~g})$ of soil from each core was taken and transferred to McCartney bottles. The moisture content of the samples were adjusted to $2 \mathrm{x}$ WHC (water holding capacity) and transferred to another set of $30 \mathrm{ml}$ McCartney bottles sealed with No 25 sub-seal. Each sample was enriched with glucose solution (3 ml each of $10 \% \mathrm{w} / \mathrm{v}$ glucose) and incubated on a roller bed at $20^{\circ} \mathrm{C}$. Head space gas sample was taken from each bottle at 2, 4 and 6 hours intervals and analysed by gas chromatography for $\mathrm{CO}_{2}$.

\section{Seed germination tests}

A total of 60 cores were prepared, i.e. 12 for each ADC amended soil. Fifteen soil cores comprising three replicates for each amended soil were removed prior to incubation (week 0 ). The remaining cores were preincubated at $15^{\circ} \mathrm{C}$ before planting seeds for germination tests. Fifteen soil cores (i.e. three replicates for each amendment) were removed after week 1 , week 3 , and week 12 of incubation. Removed cores were stored at $4^{\circ} \mathrm{C}$ prior to seed germination tests. Seed germination tests were carried out as described by Levy and Taylor, (2003). Results were expressed in terms of germination index, GI, defined as:

$\mathrm{GI}=(\%$ seed germination $) \times(\%$ root growth $) \times 100$ (Tiquia and Tam, 1998).

A $5 \mathrm{~mm}$ primary root elongation was adopted as the operational definition of seed germination (APHA, 1992).

\section{DNA analysis}

At the end of the incubation period described above, 1 $\mathrm{g}$ of soil was taken from each core and frozen in liquid nitrogen and stored at $-80^{\circ} \mathrm{C}$ awaiting DNA analysis. Prior to DNA studies, the soil samples were thawed and their nucleic acid extracted and purified as described by Pennanen et al., (2004). Two rounds of polymerase chain reaction (PCR) amplifications were carried out for each DNA sample using bacterial and fungal primers. 
The bacterial primer pairs used were $16 f 27 / 1494 r$ and 63fFAM/1405rVIC while the fungal primer pairs were EF3RCNL/ITS4 and ITS1fNED/ITS4PET. The PCR products were stored at $-20^{\circ} \mathrm{C}$ prior to T-RFLP. Restriction enzymes used were AluI with recognition sequences of 5'AGCTand 3'TCGA and HinfI with recognition sequences of $5^{\prime}$ GANTC and 3 'CTNAG. Restriction enzymes, dyes and associated buffers were supplied and used as instructed by Promega, (2006) to yield restriction fragments. The fragments were sequenced and peaks obtained analysed statistically.

\section{Statistical Analysis}

Data obtained from soil respiration and microbial biomass incubations were analysed using descriptive statistics. Principal component analysis (PCA) was used to interpret the complex patterns produced from T-RFLP profiles with ANOVA applied to principal component scores to assess significance of effects (Deng et al., 2009). Thus, for the data of DNA analysis, multivariate analysis (MA) was carried out to determine changes in community structure of soil samples containing different compost amendments by comparing their terminal restriction fragments, using Genstat software (version 9.2 VSN International Ltd
Hemel Hempstead). Differences between the results were considered significant for a value of $P<0.05$. Principal scores obtained were subjected to analysis of variance (ANOVA) in Microsoft Excel to test for significant differences in soil samples. For the calculation of community structure from T-RFLP profiles were treated as species and their relative areas served as a measure of relative abundance (Pennanen et al., 2004; Blackwood et al., 2003).

\section{RESULTS AND DISCUSSION}

Anaerobic digestion of waste combinations (batch digestion)

The $\mathrm{pH}$ profile in Figure 1 shows that only cultures $\mathrm{A}$ recorded $\mathrm{pH}$ values that are lower than the minimum $\mathrm{pH}$ of 6 recommended for good digestion. It can also be seen that $\mathrm{pH}$ resilience was greater in cultures composed mainly of GW. Where FW dominates as in culture $A$ rapid acidification was observed causing excessive accumulation of volatile fatty acids (VFAs) and hence low $\mathrm{pH}$, a condition that may have inhibited methanogenic activity. In contrast cultures with high GW content showed slow acidification, which may be due to the higher proportion of less readily degradable substrates at the end of the 15 days digestion.

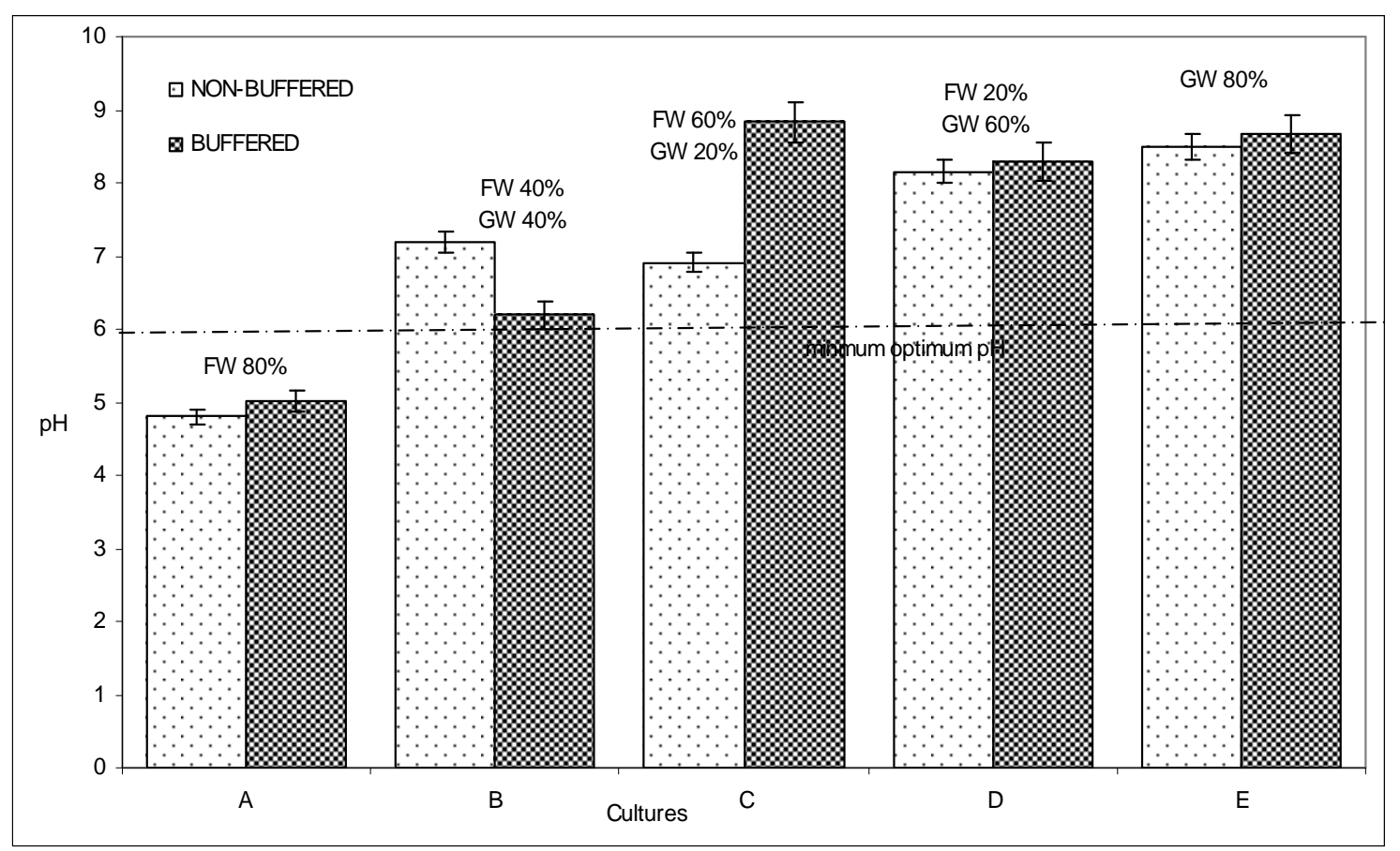

Figure $1 \mathrm{pH}$ in buffered and non-buffered cultures. Dotted lines represent the minimum optimum pH. Error bars are calculated as the standard deviation of individual data points $(n=3)$.

The Results in Figure 1 suggests that, $\mathrm{pH}$ stability during digestion depended on the feedstock which increased with increase in the GW proportion. Where FW dominated the feed composition, which is a more readily biodegradable waste material, rapid acidification was observed causing excessive accumulation of volatile fatty acids (VFAs) and resulting in low $\mathrm{pH}$ which adversely affected digestion of the cultures. In contrast, cultures with high GW content (i.e. less readily biodegradable waste material) showed slow acidification, resulting in neutral $\mathrm{pH}$ during digestion. Thus waste composition may be a useful tool for $\mathrm{pH}$ regulation in anaerobic digestion processes. The need for chemical $\mathrm{pH}$ correction during anaerobic digestion of OFMSW decreases with increase in the GW proportion of the feedstock. Total volatile solid (TVS) reductions occurred in both buffered and non-buffered cultures as shown in Figure 2. Both buffered and non buffered culture $B$ recorded the highest solid reduction of about $60 \%$ compared to less than $20 \%$ in E cultures. 
No significant differences in Volatile (VS) reductions were observed in A cultures. Figure 2 also shows that the higher the GW content the lower the TVS reduction during the experimental period. This may be due to the low degradability of GW coupled perhaps by toxicity due to free ammonia. The low TVS reduction observed in culture A was believed to be due to low pH values in those cultures as shown in Figure 1. The pH values of about 5 recorded in both buffered and non-buffered can adversely affect the digestion process as also observed by Garcia-Heras, (2003).

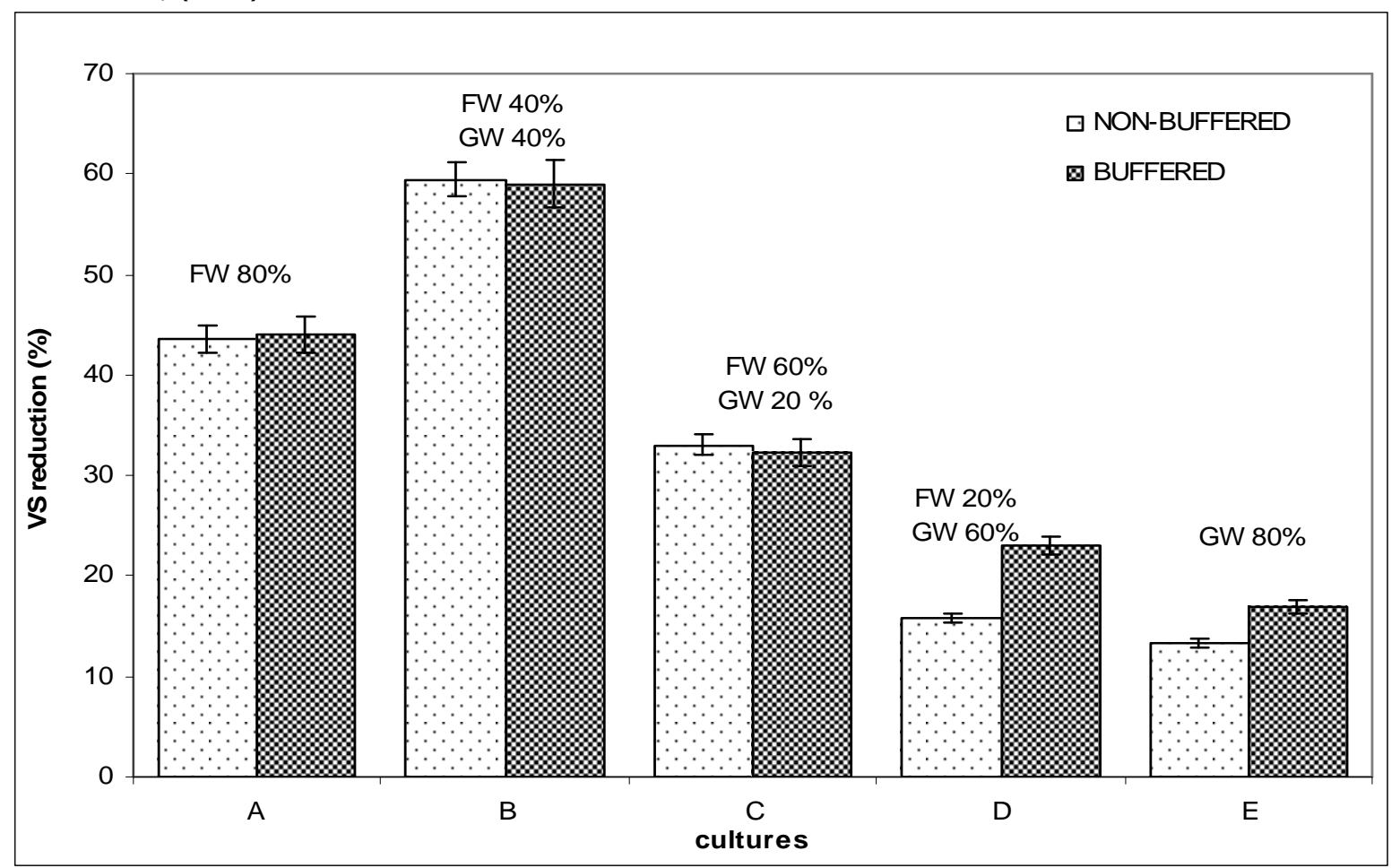

Figure 2 Total volatile solids reduction in buffered and non-buffered cultures. Error bars are calculated as the standard deviation of individual data points $(n=3)$.

It was also found that the moisture content of the anaerobic digestates decreased with increase in GW content of the raw feedstock. Thus an appropriate selection of raw waste composition can reduce the cost of post digestion dewatering which may be necessary for the final disposal of the digestates.

In general, gas production followed the same pattern as volatile solids reduction, which decreases with increasing GW content of the feedstock. The higher the FW content of the feedstock the greater the volume of biogas recovered per organic solids removed.

\section{Production of anaerobic digestate compost (ADC)}

The production of anaerobic digestate compost involved aerobic post-treatment of the residual digestate obtained from digestion of feedstock combination B (i.e. FW 40\%, GW 40\%, AS 20\%), which was found to produce the best results in terms of solid reduction, biogas production and $\mathrm{pH}$ stability. TVS reduction of $33 \%$ was achieved after the 15-day digestion process, with average biogas yield of 0.13 $\mathrm{m}^{3} / \mathrm{kgTVS}$ and final digestate $\mathrm{pH}$ TS, TVS and Carbon: Nitrogen ratio (C:N) ratio of $6.7,19.1 \%$, $11.7 \%$ and $23: 7$ respectively.
During the aerobic treatment, both TS and VS increased with aeration time, due probably to one and/or a combination of precipitation out of solution, evaporation and microbial growth. A decrease in C:N ratio with increasing aerobic treatment was also observed, due probably to organic compound degradation. At the end of aerobic post-treatment of combination $\mathrm{B}$, the ADC obtained had TS $45 \%$, pH 7.8 and $\mathrm{C}: \mathrm{N}$ ratio $12: 7$, all within values recommended for good composts (WRAP, 2003). C:N ratio and TS/TVS were found to be less variable at compost stability. These parameters, including $\mathrm{pH}$ can be used as indicators to assess compost maturity and stability. It is worth noting that aeration was carried out intermittently for 5 hours on a daily basis for technical reasons (reactor size and feedstock volume). A more efficient aeration system could have brought about stability in a shorter period.

\section{Soil respiration and biomass}

The results of respiration tests are shown in Figure 3. It can be seen that soil bioactivity increased with length of incubation and increased ADC content. For instance, in soils amended with 50 and $100 \mathrm{t} \mathrm{ha}^{-1}$ of $\mathrm{ADC}, \mathrm{CO}_{2}$ evolution increased from about 0.2 and 0.4 $\mu \mathrm{gCO}_{2} / \mathrm{g} / \mathrm{h}$ before incubation to about 0.5 and 1.2 $\mu \mathrm{gCO}_{2} / \mathrm{g} / \mathrm{h}$ respectively after 80 days of incubation. 


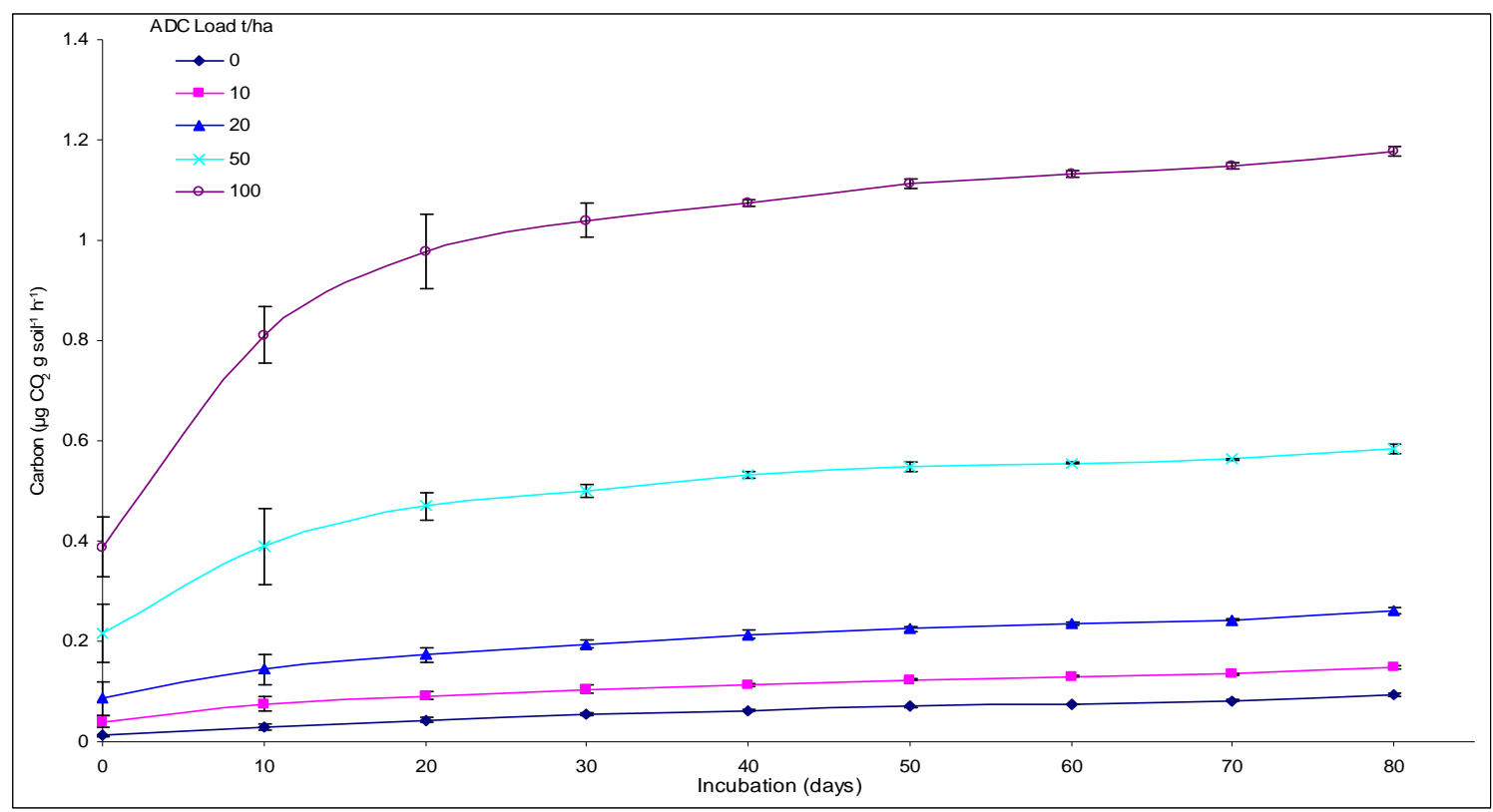

Figure 3 Soil respiration in ADC amended and non-ADC amended soils. Bars represent mean standard deviation $(n=6)$

The slow and continuous carbon release, observed after the $20^{\text {th }}$ day was probably an indication of the depletion of most of the readily biodegradable organic matter in the ADC. Slow decomposing organic fertilizers are considered stable and most suitable for sustainable soil fertility and increased productivity (Calderon et al., 2004; Godley, 2004; Debosz et al., 2002). As expected, soil biomass also increased with increasing ADC amendments as shown in Figure 4.

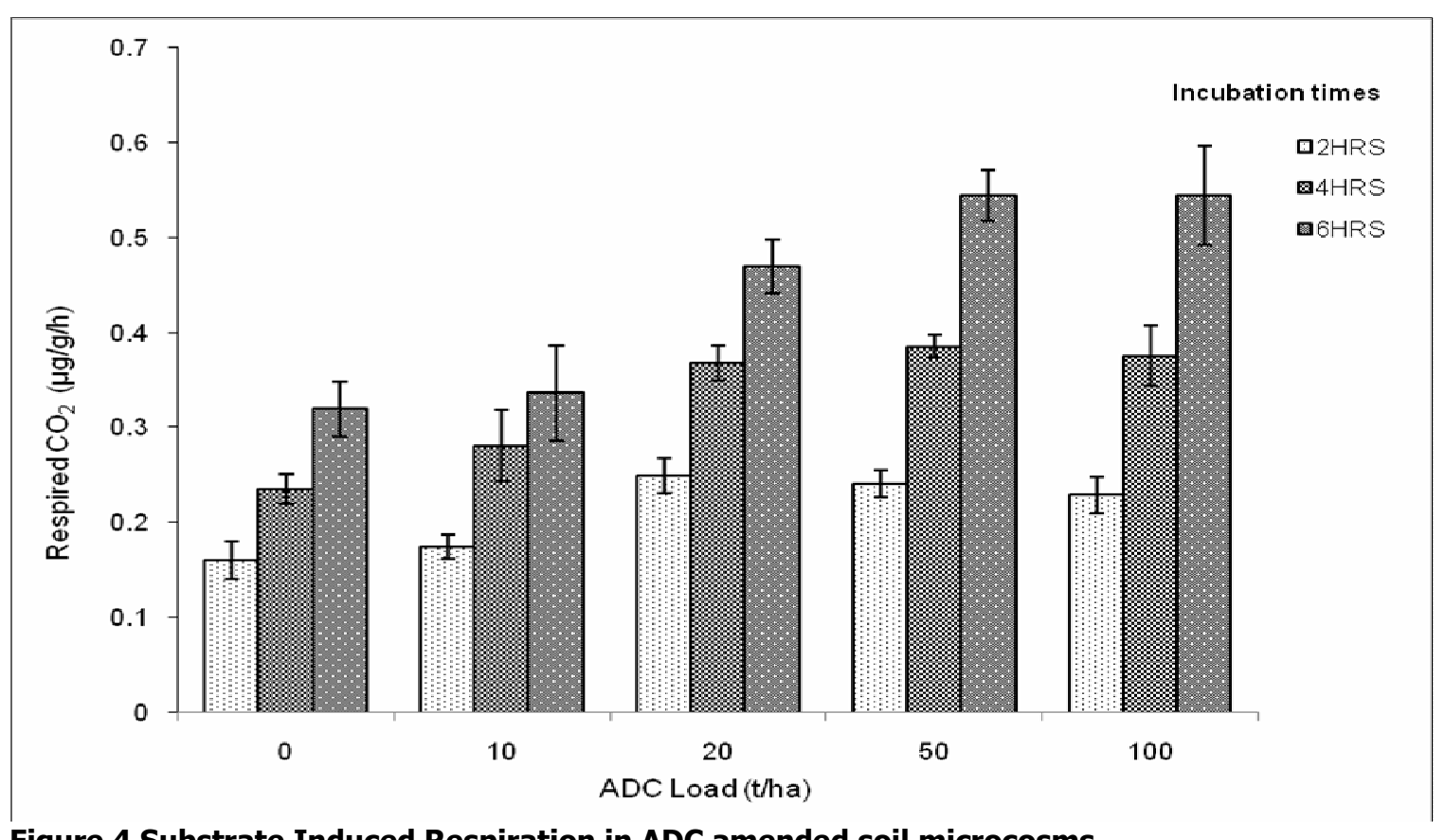

Figure 4 Substrate Induced Respiration in ADC amended soil microcosms

Seed germination tests with ADC amended soils Figure 5 shows the results of seed germination tests using liquid extracts from soils amended with variable loading rates of $A D C$ at different incubation times. The non-incubated soil samples amended with ADC load of $100 \mathrm{t} \mathrm{ha}^{-1}$ recorded the lowest germination index of $52 \%$ which subsequently increased to $124 \%$ after twelve weeks of incubation. Soils amended with ADC loading of $10 \mathrm{t} \mathrm{ha}^{-1}$ showed the highest increase in seed germination after 12 weeks of incubation. Generally, all ADC amended soils performed better than control (soil unamended with $A D C$ ). The results suggest that incubation seemed to reduce phytotoxicity through the reduction of available biodegradable matter in the compost. 


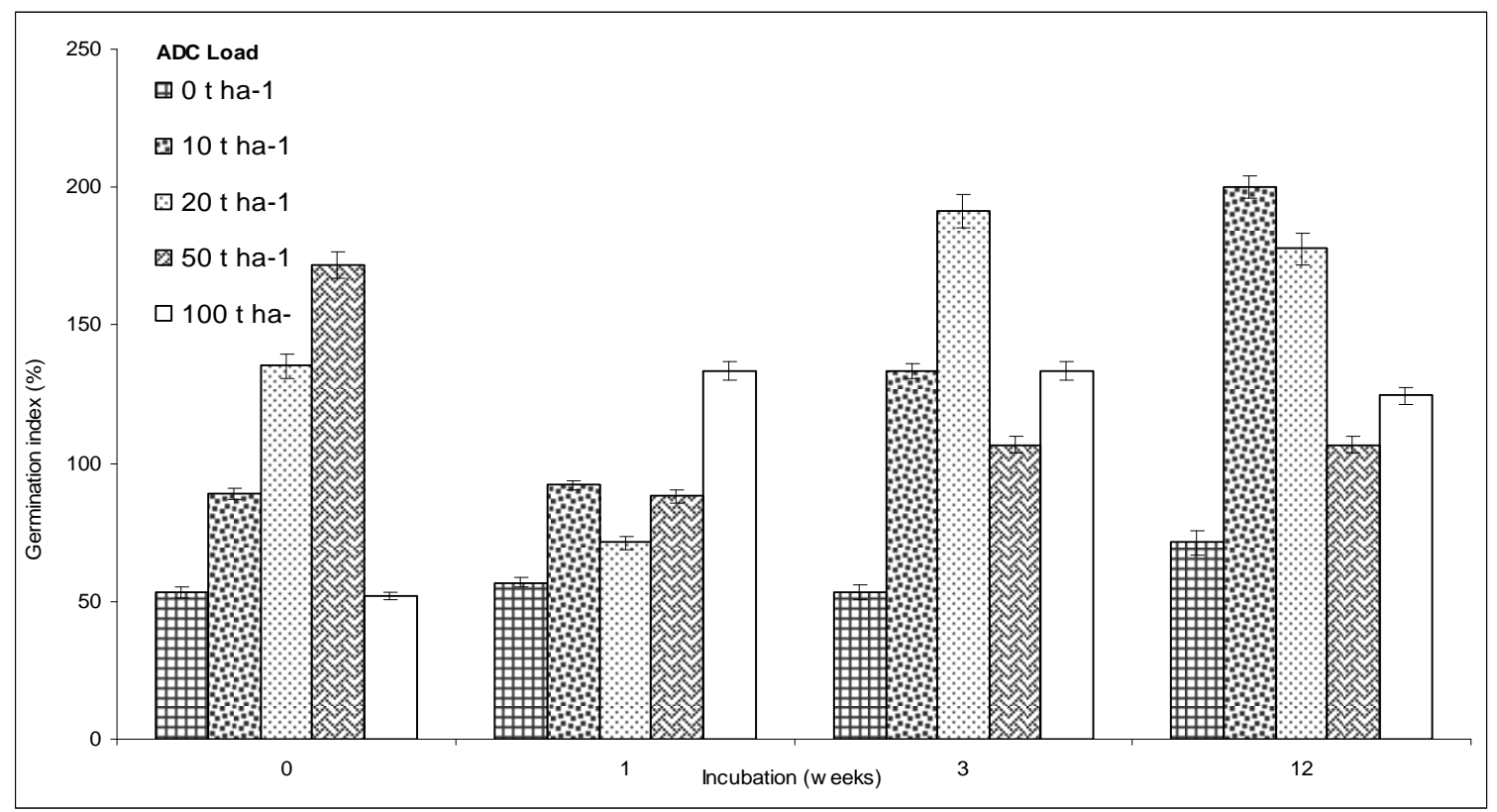

Figure 5 Seed germination of undiluted soluble extracts of ADC amended soils.

Generally, ADC amended soils showed higher seed germination than unamended soil, however seed germination increased with decreasing dilution and increasing incubation time as further illustrated in Figures 5 and 6 . The non ADC amended soil controls showed no significant change in seed germination

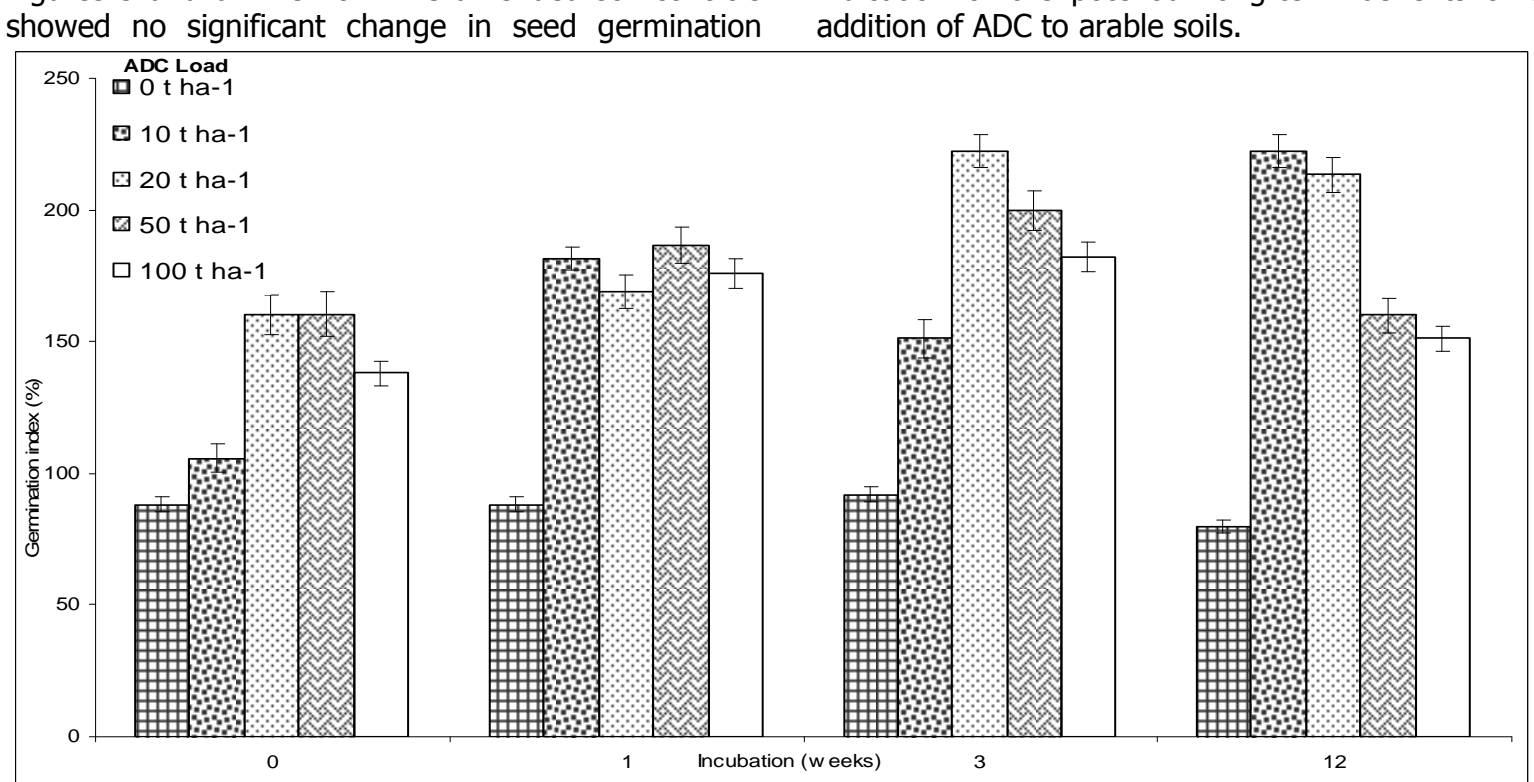

Figure $\mathbf{6}$ Seed germination in $\mathbf{5 0 \%}$ diluted soluble extracts of ADC amended soils.

\section{Microbial community structure}

Figure 7 illustrates the diversity of soil community structure of AluI digests. The results showed significant changes in diversity of bacterial populations with increasing dilution or incubation time. The high seed germination indexes observed in ADC amended soils and especially in 50\% diluted soluble extracts which in all cases was higher than the controls is an indication of the potential long-term benefits of the addition of ADC to arable soils. in ADC amended microcosms compared to nonamended controls with a variation of $37 \%$. Figure 6 shows the principal coordinate scores of HinfI digests. 


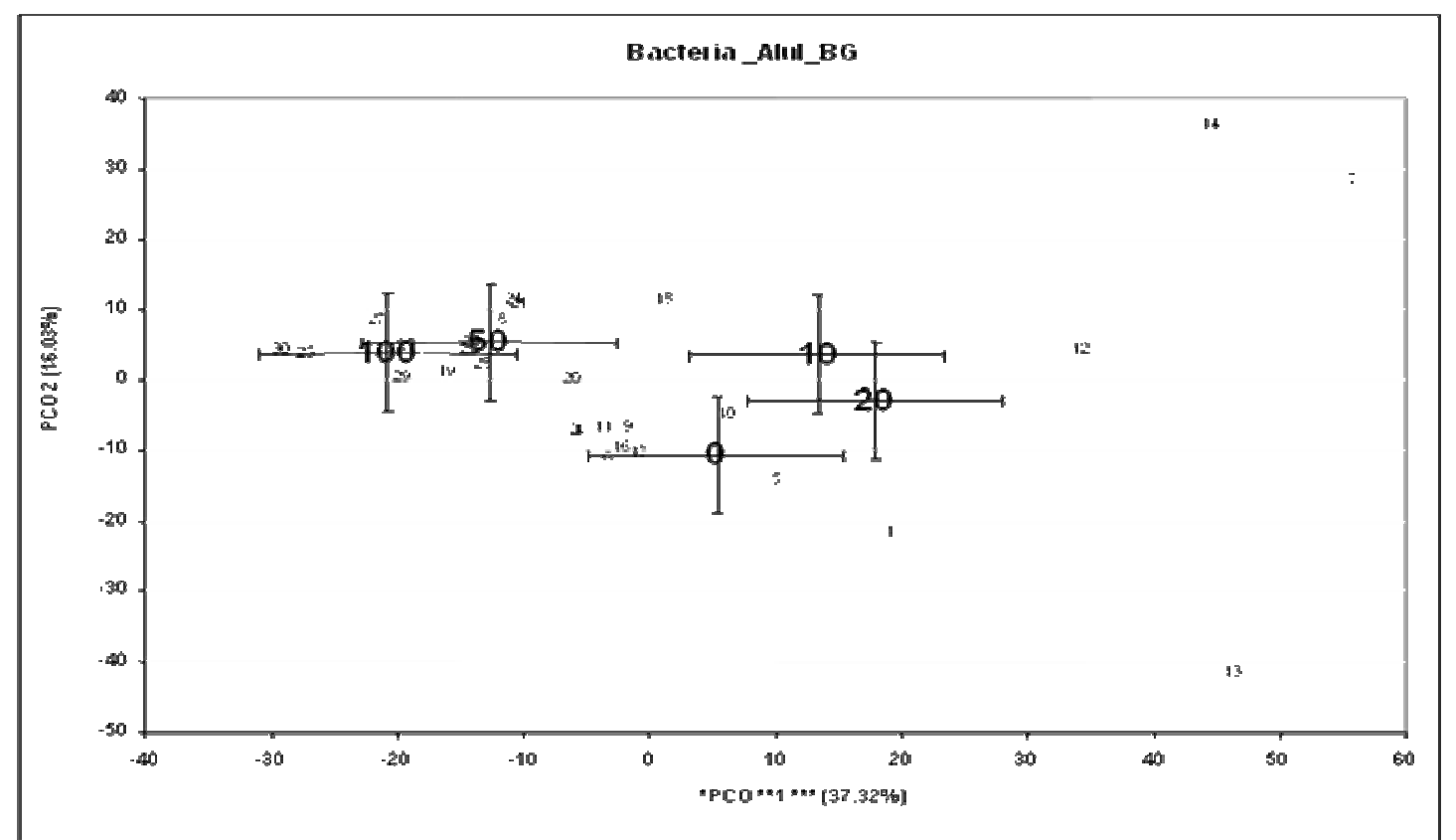

Figure 7 Principal co-ordinate scores of sequenced AluI restriction enzyme digest fragments where small numbers refer to microcosm with compost amendment as follows: $1-6$, no compost; $7-12,10 \mathrm{t} \mathrm{ha}^{-1} ; 13-18$, $20 \mathrm{t} \mathrm{ha}^{-1} ; 19-24,50 \mathrm{t} \mathrm{ha}^{-1} ; 25-30,100 \mathrm{t} \mathrm{ha}^{-1}$ the larger numbers refer to compost loading in tha ${ }^{-1}$ Bars represent mean population distribution $(n=6)$

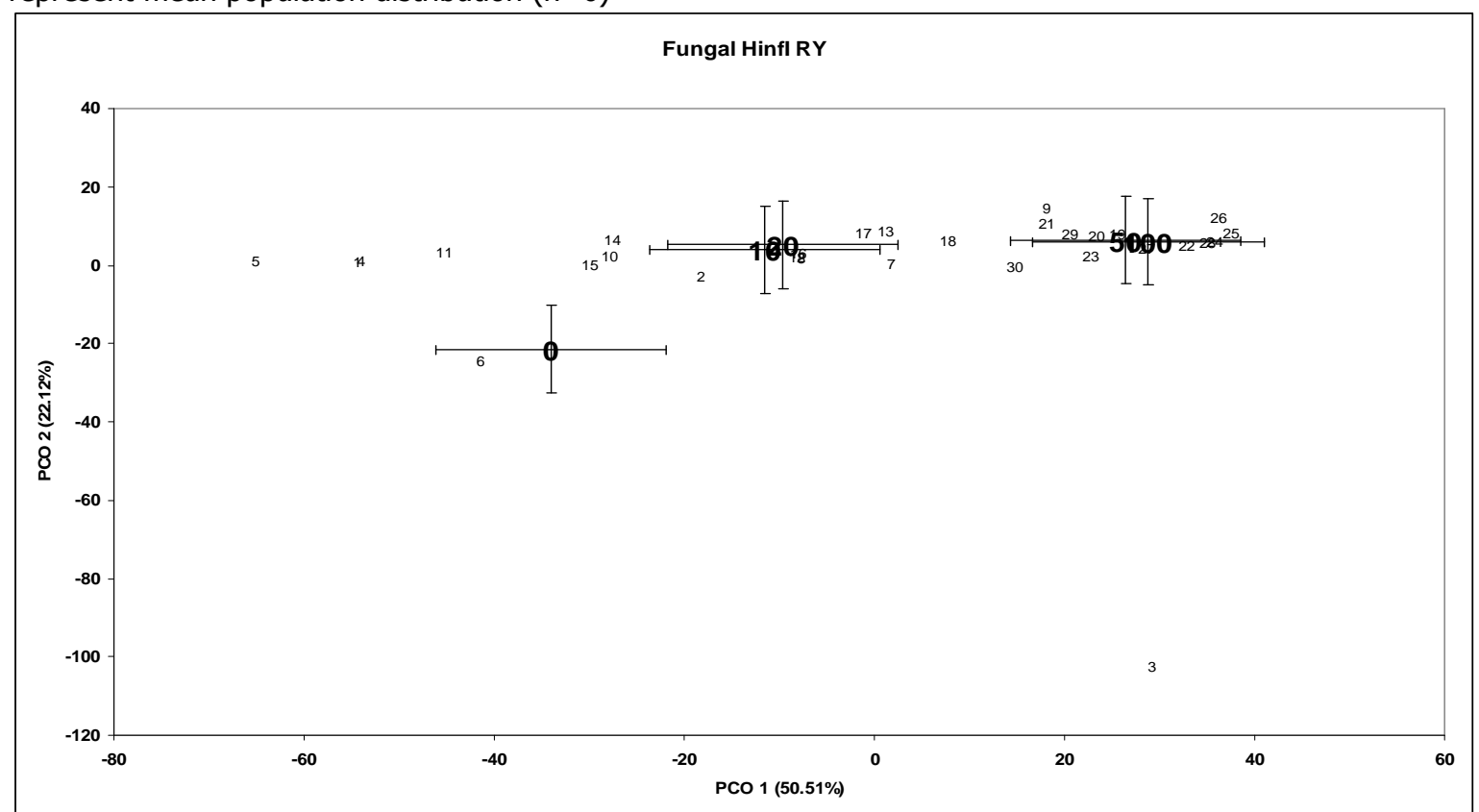

Figure 8 Principal co-ordinate scores of sequenced HinfI restriction enzyme digest fragments where small numbers refer to microcosm with compost amendment as follows: $1-6$, no compost; $7-12,10 \mathrm{t} \mathrm{ha}^{-1} ; 13-18$, $20 \mathrm{t} \mathrm{ha}^{-1} ; 19-24,50 \mathrm{t} \mathrm{ha}^{-1} ; 25-30,100 \mathrm{t} \mathrm{ha}^{-1}$ The larger numbers refer to compost loading in tha ${ }^{-1}$ Bars represent mean population distribution $(n=6)$

The figures (7 and 8$)$ suggests that ADC amendments showed greater impact on the structure of fungal communities compared to those of bacteria with a variation of $51 \%$. Little variation was observed in microcosms with low $\left(10,20 \mathrm{t} \mathrm{ha}^{-1}\right)$ ADC amendments, whose means formed a cluster distinctively separate from the other cluster formed by microcosms with higher $\left(50,100 \mathrm{t} \mathrm{ha}^{-1}\right)$ ADC amendments. This indicate that the higher the ADC application rates, the greater the variations and consequently the diversity of soil populations.

Generally, the 18S rRNA fragments showed greater variations than those of $16 \mathrm{~S}$ rRNA. The DNA analysis indicates that restriction fragments show greater variation in fungi $(51 \%)$ than in bacteria (37\%) suggesting that ADC amendment has greater effect on fungi than bacteria. 


\section{CONCLUSION}

This study shows that the digestion of feedstock comprising equal proportion of food and green wastes is suitable for biogas recovery because of its superior natural buffering capacity and high solid reduction. Feedstock mix can thus be used to minimise chemical $\mathrm{pH}$ buffer correction. Post-aerobic treatment or aerobic digestion of anaerobically digested organic wastes increased the stability and quality of resulting compost. $\mathrm{pH}$ and $\mathrm{C}: \mathrm{N}$ ratio were found to be useful indicators for monitoring compost stability and quality during aerobic digestion. Generally the study demonstrated that application of Anaerobic Digestate Compost (ADC) improved the biological properties of arable soils.

The study also reveals that ADC can increase the bioactivity of soil microbial populations. Seed germination in ADC amended soils increased with dilution and incubation time, suggesting that lower ADC application rates and longer lag periods between soil applications and planting can improve the benefits of $A D C$ as soil amendment.

\section{REFERENCES}

APHA (American Public Health Association), (1992). Standard Method for the examination of water and wastewater, Eighteenth edn., Greenberg A.E., Clesceri, L.S. and Eaton, A.D. (Eds), American Public Health Association, Washington, DC, USA

Blackwood C.B., Marsh, T., Kim, S., and Paul E.A., (2003). Terminal restriction fragment length polymorphism data analysis for quantitative comparison of microbial communities. Applied Environmental Microbiology, 69, 926932

Bolzonella, D., Pavan, P., Mace M., and Cecchi, F., (2006). Dry anaerobic digestion of differently sorted organic municipal solid waste: a full scale experience, Water Science Technology, 53 (8), 7-22

Calderón, F.J., McCarty, GW., Van Kessel, JAS., and Reeves III., JB., (2004). Carbon and Nitrogen Dynamics Incubation of Manured Soil, Soil Science Society of America Journal, 15921599

CEC (Council of European Communities) Landfill Directive, (1999). Directive on landfill of waste (1999/31/EC) Official Journal L 182

Crecchio, C., Curci, M., Pizzigallo, M.D.R., Ricciuti, P., and Ruggiero, P., (2004). Effects of municipal solid waste compost amendments on soil enzyme activities and bacterial genetic diversity. Soil Biology Biochemistry, 36, 15951605

Debosz, K., Peterson, S.O., Kure, L.K., and Ambus P., (2002). Evaluating Effects of Sewage Sludge and Household Compost on Soil Physical, Chemical and Microbiological Properties, Applied Soil Ecology, 19,237-248

DEFRA (Department for Environment Food and Rural Affairs) (2004). First Soil Action Plan for
Whilst soil biomass increased with ADC amendments, the diversity of soil populations increased with increasing amounts of ADC. Furthermore, ADC addition seemed to have greater effect on fungi than bacteria diversity possibly due to their (fungi) superior functional diversity.

In general, this study has demonstrated that depending on the raw waste composition and the nature and duration of biological treatment received, OFMSW can be associated with high biogas yield, soil fertility and productivity. Whilst the study has demonstrated the suitability of anaerobic digestate compost for soil management applications, the holistic approach employed in this study can lead to sustainability in management of OFMSW.

\section{Acknowledgement}

The authors wish to acknowledge financial and material assistance provided by the European Social Fund and Scottish Crop Research Institute, Invergowrie, Dundee, United Kingdom

England 2004-06, DEFRA soil activities Available Online From: http://www.defra.gov.uk/environment/landlia bility/soil/index..htm\#Research [Cited 31/03/2008]

Deng, H., Zhang, B., Yin, R., Wang, H.C., Mitchell, S.M., Griffiths, B.S., and Daniell, T.J., (2009). Long-Term effect of re-vegetation on the microbial community of a severely eroded soil in sub-tropical china, Plant and Soil, 328 $(1-2), 447-458$

Godley, A.R., (2004). Factors affecting the soil microbial quality measurements of biomass quotient and respiration quotient, Journal of Chartered Institution of Waste Management, 18 (2), 73-79

Hartmann, H., and Ahring, B.K., (2006). Strategies for the anaerobic digestion of the organic fraction of municipal solid waste; an overview, Water Science Technology, 53 (8), 7-22

Hoekstra, N.J., Bosker, T., and Lantiga, E.A., (2002). Effects of cattle dung from farms with different feeding strategies on germination and initial root growth of cress (Lepidium sativum L.), Agriculture Ecosystems and Environment, 93: 189 - 196

Jimenez, E.I., and Garcia, V.P., (1989). Evaluations of city refuse compost maturity: A Review. Biological Wastes, 27 (2): $115-142$

Kayhanian, M., (1995). Biodegradability of the organic fraction of municipal solid waste in a highsolids anaerobic digester. Waste Management \& Research. 13, 123 - 136

Kowaljow, E., and Mazzarino, M.J., (2007). Soil restoration in semi-arid Patagonia: Chemical and Biological response to different compost quality, Soil Biology and Biochemistry, 39 (7): 1580-1588 
Levy, S.J., and Taylor, B.R., (2003). Effect of pulp mill solids on three composts on early growth of tomatoes. Bioresource Technology, 89, 297 305

Lin, Q., and Brookes, P.C., (1999). Comparison substrates induced respiration, selective inhibition and biovolume measurements of microbial biomass and its community structure in Unamended, ryegrass-amended, fumigated and pesticide treated soils. Soil Biology and Biochemistry, 31, 1999-2014

Marsh, T.L., (1999). Terminal restriction fragment length polymorphism (T-RFLP): an emerging method of characterizing diversity among homologous populations of amplification products, Current Opinion in Microbiology. 2, 323-32

Mata-Alvarez, J., Macé, S., and Llabrés P., (2000). Anaerobic Digestion of Organic Solid waste: An overview of research achievements and perspectives, Bioresource Technology, 74, 316

Mata-Alvarez, J., Cecchi, F., Pavan, P., and Llabrés P., (1990). The performances of digesters treating organic fraction of municipal solid waste different sorted, Biological Wastes, 33, 181-199

Murillo, J.M., Cabrera, F., Lopez, R., and MartinOlmedo, P., (1995). Testing Low-Quality Urban compost for agriculture: germination and seedling performance of plants,
Agriculture, Ecosystems \& Environment, 54, 127-135

Pennanen, T., Caul, S., Daniell, T.J., Griffiths, B.S., Ritz, K., and Wheatley, R.E., (2004). Community-level of responses of metabolically-active soil micro organisms to the quantity and quality of substrate inputs, Soil Biology and Biochemistry, 36, $841-848$

Promega, (2006). Life science catalogue

Rajbanshi, S.S., Hidekazu, E., Sakamoto, K., and Inubushi, K., (1998). Stabilization of chemical and biochemical characteristics of grass straw and leaf mix during in-vessel composting with and without seeding materials. Soil Science Plant Nutrition, 44 (4), 485-495

Ritz, K., and Wheatley, R.E., (1989). Effects of water on basal and substrate- induced respiration rates of mineral soils, Biology and Fertility of Soils, 8, $242-246$

Shiralipour, A., McConnel, D.B., Smith, W.H., (1992). Uses and benefits of MSW compost: A review and assessment, Biomass and Bioenergy, 3 (3-4), 267-279

Tiquia, S.M., and Tam, N.F.Y., (1998). Elimination of phytotoxicity during co-composting of spent pig-manure sawdust litter and pig sludge, Bioresource Technology, 65, $43-49$

Waste Resources Action Programme, (WRAP) (2003). Using compost in Agriculture and field Horticulture, Fact sheet 02. WRAP www.wrap.org [cited 15/06/05] 